\title{
Students' Perceptions and Acceptance of LEGO Robots in Syria
}

\author{
Ghaith Mqawass \\ Department of Mechatronics, Tishreen University Lattakia \\ ghaith.mqawass@gmail.com
}

\begin{abstract}
An important recent trend in education has been the integration of different technologies such as digital games, online courses, and educational robots. The development of educational robots such as LEGo Mindstorms NXT allows students to learn to build their own robots. This paper describes the human-robot interaction (HRI) focusing especially on the model LEGo Mindstorms NXT. A questionnaire among 250 Syrian school and university students was conducted to investigate the different perceptions about LEGO robots in 2016. The informants were grouped based on their age; participants in the first group were aged between 11 and 18 years while participants in the second between 19 and 24. The current study also focuses on the factors leading to the acceptance of LEGO robots. Another questionnaire was conducted to highlight what factors determine the degree of acceptance of LEGO robots by the studied groups. Significant age and gender effects were found. The results show a noticeable difference between the two age groups, with the younger group tending to accept LEGO robots more. Furthermore, it was found that male respondents show more positive reactions towards LEGO robots than females.
\end{abstract}

\section{Keywords}

LEGO - Robots - human-robot interaction - Syrian education system

Because Syria is considered a developing country, the integration of education and technology is still in its infancy. However, there are some existing

(C) MQAWASS, $2018 \mid$ DOI $10.1163 / 25430149-00101005$

This is an open access article distributed under the terms of the prevailing CC-BY-NC license at the time of publication. 
experiments, which show that this process has truly been initiated. The use of LEGO robotics has spread through multiple schools, institutions and universities in Syria. Furthermore, several local robotic activities take place annually. Students are also participating in LEGO competitions such as WRO. Nevertheless, in order to evaluate the success of the implementation of this experiment or to interpret its future outcomes, it is necessary to search for the answers to two main questions:

- Do Syrian students accept LEGO robots? If yes, how do they interact with them?

- How do Syrian students perceive these LEGO robots?

Regarding the first question, plenty of research has looked into human-robot interaction (HRI). Each study depended on a certain kind of robot and tried to determine the factors which caused user experiences to differ.

Mutlu (Mutlu et al. 2006) classifies the HRI into three groups: robot attributes (e.g., appearance and character), user's personal factors (age, gender and mental models of robots), and the nature of the task that is performed (e.g. competitive and collaborative tasks).

Another study that outlines numerous factors in determining the acceptance of a healthcare robot was published in 2009. Broadbent (Broadbent et al. 2009) categorizes the factors of acceptance into two dimensions: individual factors (age, gender, needs, experience with technology/robots, cognitive ability and education, culture, role and anxiety, and attitudes towards robots) and robot factors (appearance, humanness, facial dimensions and expressions, size, gender, personality and adaptability).

Another phenomenon that plays a major role in determining the humane acceptance and the familiarity with a robot is the 'uncanny valley'. As far as the relation between likeness and perceived familiarity is concerned, Mori (Mori 1970) argues that familiarity increases with the human likeness until an uncanny valley is reached, caused by sensitivity to perceived imperfections in near-humanlike forms. According to Mori, movement magnifies the uncanny valley.

As for the second main question, the findings from past foreign studies showed that educational robots have become an important learning technology and a subject for students to study.

Liu (Liu 2010) has conducted important research in which the researcher examined young adults' perceptions of educational robots. Liu's study categorized the adolescence's perceptions into three groups: as a plaything, a source of employment or as a way to high technology. Liu's study (Liu 2010) also showed that while males tended to regard learning about robotics as a 
source of employment and a way to high technology, both females and males perceived educational robots as a plaything.

According to an article published in Berkshire Encyclopedia of HumanComputer Interaction (Bainbridge et al. 2004), researchers at the Royal Institute of Technology in Stockholm, Sweden, have been working on the development of a robot to assist users with everyday tasks such as fetching and delivering objects in an office environment. A general survey was conducted to determine what people would like such a robot to do, to look like, how they would prefer to communicate with it, and generally how they would respond to it. A large proportion of the respondents were positive about having help from the robot with some kinds of basic household tasks; the majority preferred the service robot not to act independently, and speech was their preferred mode of communication. Experiments with an early robot prototype showed that people had difficulty understanding the robot's orientation due to its appearance (it was cylindrical in shape, with no clearly defined front), in communicating spatial directions, and in understanding what the robot was doing due to lack of feedback.

Research conducted by Alami et al. (Sisbot et al. 2007) shows another point where the importance of $\mathrm{HRI}$ arises. It urges us to consider the amount of threat a human feels about a given robot configuration. Hence, as the danger of injuries increases with high velocities, it is better to slow down the robot motion.

The intention of the current study is to determine the factors that contribute to Syrian students' acceptance of LEGO robots and to compare it with factors found in previous studies. Another intention is to find and classify the major perceptions of students and then extrapolate the importance of LEGO robots for Syrian society in general.

250 school and university students aged between 11-24 were asked to take part in the questionnaire, which was conducted in November 2016. A total of 100 participants agreed and were consequently recruited and divided into two age groups. Group (A) consisted of 42 participants (aged 11-18 years) of mean age 15.55 years (SD 2.3 years), with 22 males and 20 females. Group (B) had 58 participants (aged 19-24) of mean age 21.4 years (SD 26 years), with 35 males and 23 females. Most students were from Damascus and Latakia (forming $82 \%$ of the total number).

All participants had previous experience with LEGO robots. Their experience varied due to attending different LEGO robot courses at school. They learned to build and program robots to do simple tasks like following a line or 
carrying some objects. Another experience is being a participant or a coach in the World Robot Olympiad (wRo) where they build and program the robots to do more complex and time-consuming tasks like planting trees and classifying objects in a certain order. Two questionnaires were developed to achieve the research purpose. The first one was a computer-based questionnaire while the second one was based on interviews with participants that took place in December 2016. The first questionnaire included two questions. Participants were asked on a computer based questionnaire to rate their experience with LEGO using each of the following scales: likeness of LEGO robots on a ten-point dislike versus like scale, ten-point unhuman vs humanlike scale. The second questionnaire consisted of a four-point Likert scale, which was developed by interviewing the participants, included four subscales that described educational robots as a plaything, learning of robotics as a source of employment, learning of robotics as a source of development of mental and personal skills, and as a way to high technology. The factor loading was high (ranging from 0.739 to 8.931) and the reliability of the questionnaire was high (ranging from 0.836 to 0.855 ). The interscale coefficient of the correlation between each scale of this questionnaire was suitable (ranging from 0.667 to 0.775 ).

\section{Results}

Table 1 shows the ratings of LEGO robots between age groups. Group (A) result on Like vs Dislike scale has a 9.17 mean, which is obviously greater than Group B which has a 8.19 mean. Another noticeable result from Table 1 is that the mean value of group (A) on unhuman vs humanlike scale is considerably greater than Group B mean value.

Table 2 shows that males (9.17 M, $2.43 \mathrm{SD}$ and 3.69 M, 1.94 SD) reported greater mean values on both scales in comparison with females (8.19 M, 2.13 SD and $2.69 \mathrm{M}, 1.58 \mathrm{SD}$ ).

TABLE 1 Ratings of LEGO robots between age groups

\begin{tabular}{|c|c|c|c|}
\hline Scale & Scale Indication & $\begin{array}{l}\text { Group (A) } \\
\text { Mean (SD) }\end{array}$ & $\begin{array}{l}\operatorname{Group}(B) \\
\operatorname{Mean}(S D)\end{array}$ \\
\hline Like versus Dislike & $\begin{array}{l}1=\text { totally dislike } \\
10=\text { totally like }\end{array}$ & $9.17(2.43)$ & $8.19(2.13)$ \\
\hline $\begin{array}{l}\text { unhuman versus } \\
\text { Humanlike }\end{array}$ & $\begin{array}{l}1=\text { Unhuman (totally not familiar) } \\
10=\text { Humanlike (totally familiar) }\end{array}$ & $3.69(1.94)$ & $2.69(1.58)$ \\
\hline
\end{tabular}


TABLE 2 Ratings of LEGO robots based on gender

\begin{tabular}{|c|c|c|c|}
\hline Scale & Scale Indication & $\begin{array}{l}\text { Males } \\
\text { Mean (SD) }\end{array}$ & $\begin{array}{l}\text { Females } \\
\text { Mean }(S D)\end{array}$ \\
\hline Like versus Dislike & $\begin{array}{l}1=\text { totally dislike } \\
10=\text { totally like }\end{array}$ & $9.12(2.63)$ & $7.67(1.73)$ \\
\hline Unhuman versus & $1=$ Unhuman (totally not familiar) & $4.91(1.97)$ & $1.68(1.07)$ \\
\hline Humanlike & $10=$ Humanlike (totally familiar) & & \\
\hline
\end{tabular}

TABLE 3 Students' perceptions of educational robots according to gender

\begin{tabular}{|c|c|c|c|c|c|c|}
\hline & \multicolumn{2}{|l|}{ All } & \multicolumn{2}{|l|}{ Male } & \multicolumn{2}{|c|}{ Female } \\
\hline & $\mathbf{M}$ & SD & $\mathbf{M}$ & SD & $\mathbf{M}$ & SD \\
\hline Plaything & 3.66 & 0.78 & $3 \cdot 76$ & 0.81 & 3.01 & 0.63 \\
\hline Source of employment & 3.21 & 0.65 & $3 \cdot 34$ & 0.72 & $3 \cdot 5^{6}$ & 0.69 \\
\hline $\begin{array}{l}\text { Source of development of mental skills } \\
\text { and personality }\end{array}$ & 2.93 & $0.5^{8}$ & 2.97 & 0.69 & 2.87 & 0.61 \\
\hline Way to high technology & 2.99 & 0.68 & 3.11 & 0.71 & 2.85 & 0.66 \\
\hline
\end{tabular}

TABLE 4 The main perceptions of Syrian students on educational robots and learning robotics

\begin{tabular}{lll}
\hline Category & Number of responses & \% \\
\hline Plaything & 33 & 33 \\
Source of employment & 15 & 15 \\
Source of development of mental skills and personality & 65 & 65 \\
Way to high technology & 47 & 47
\end{tabular}

Table 3 shows that males have a slightly higher tendency to consider robots as 'toys', whereas females are slightly more likely to consider learning about robots as a source of future employment.

Table 4 presents Syrian students' interview responses, which are grouped into four categories for representing their perceptions of educational robots. Some students' responses overlap in more than two categories. For example, a 21 years old student said: 
I learn robots for three reasons: it helps me improve my programming and mechanical skills, it keeps me in touch with high tech that is being developed continuously and it might also help me to become a robotic engineer in future.

\section{Discussion}

This experiment investigated the factors that contribute in determining Syrian students' acceptance of educational robots (LEGO robots in specific). The results emphasize that the younger group tends to like more and feel more familiar with LEGO robots. The higher educational level, which means a greater technical experience of the older group, can explain why they do not like LEGO robots. These robots might seem to them as toys or basic and simple technology in comparison to the more sophisticated technologies they use in universities. So, unlike the findings of the previous study by Kuo (Kuo et al. 2009) where age was not a significant factor in determining the acceptance of a healthcare robot, major difference between the two age groups' reactions towards LEGO robots is marked here. This outcome agrees with the findings of Scopelliti's and Giuliani's (Scopelliti et al. 2005) study where age significantly determined user acceptance of domestic robots.

From another perspective, males obviously appear to have attitudes and reactions that are more positive towards LEG O robots than females do. Subsequently, gender plays a major role in students' acceptance of educational robots. This matches what Kuo (Kuo et al. 2009) found in his study and opposes the findings that Scopelliti and Giuliani explained in their research (Scopelliti et al. 2005).

The data presented in Table 4 shows that Syrian students primarily perceive LEGO educational robots as a source for developing mental and personal skills $(65 \%)$ and next as a way to high technology $(47 \%)$.

Another finding is that a greater number of males tended to regard the learning of LEGO robots as a form of play while a greater number of females tended to consider learning of LEGO robots as a source of employment.

\section{Conclusion}

The results of this experiment suggest that both age and gender are vital factors in determining the students' acceptance of LEGO robots. The results also put in order the students' motivations learning with LEGO robots: 
students perceive the learning of LEGO robots as a way of developing mental and personal skills. Further research can be done to develop and modify the methods of teaching LEGO robots at schools and universities depending on the acceptance factors discussed in this research. Cultural differences, such as local traditions and work environment, that distinguish Syria from other robot-dependent communities help us to understand the importance of this research on a local scale. For example, many Syrian families trust traditional careers like medicine and pharmacy more than robotic engineering. In addition, many parts of Syria are not familiar at all with the new field of robotics. Considering these factors could improve the efficiency of the robotics educational process. It also might lead the Syrian society to accept the use of different robots in many other fields.

\section{Bibliography}

Alami, R., Albu-Schaeffer, A., Bicchi, A., Bischoff, R., Chatila, R., De Luca, A., De Santis, A., Giralt, G., Hirzinger, G., Lippiello, V., Mattone, R., Sen, S., Siciliano, B., Tonietti, G., Villani, L. (2006): Safe and Dependable Physical Human-Robot Interaction in Anthropic Domains: State of the Art and Challenges. Conference paper presented at and published in 2006 IEEE/RSJ International Conference on Intelligent Robots and Systems. Beijing, China.

Bainbridge, W.S. (2004): Berkshire Encyclopedia of Human-Computer Interaction, Human-Robot Interaction. Great Barrington, Massachusetts: Berkshire Publishing Group.

Broadbent, E., Stafford, R., MacDonald, B. (2009): Acceptance of Healthcare Robots for the older population: Review and Future Directions. In International Journal of Social Robotics, 1: 319-330. Dordrecht, Netherlands: Springer Publishing.

Kuo, I. Han, Rabindran, J.M., Broadbent, E., Lee, Y.I., Kerse, N., McAulay, R., Stafford, Q. and MacDonald, B.A. (2009): Age and gender factors in user acceptance of healthcare robots. Conference paper presented and published at RO-MAN - The 18th IEE International Symposium on Robot and Human Interactive Communication, pp. 214-219. Toyama, Japan.

Liu, E.Z.F. (2010): Early Adolescents' Perceptions of Educational Robots and Learning of Robotics. In British Journal of Educational Technology, 41: 44-47. London, United Kingdom: Wiley Publishing.

Mori, M. (1970): Bukimi no tani - the uncanny valley. In Energy, 7: 33-35. Amsterdam, Netherlands: Elsevier.

Mutlu, B., Osman, S., Forlizzi, J., Hodgins, J., Kiesler, S. (2006): Task Structure and User Attributes as Elements of Human - Robot Interaction Design. Conference paper 
presented and published at RO-MAN - Proceedings of the 15th IEEE International Symposium of Robot Human Interactive Communication. Hatfield, United Kingdom.

Scopelliti, M., Giuliani, M.V., Fornara, F. (2005): Robots in a Domestic Setting: a Psychological Approach. In Universal Access in the Information Society, 4(2): 146-155. Dordrecht, Netherlands: Springer Publishing.

Sisbot, E.A., Marin-Urias, L.F., Alami, R., Siméon, T. (2007): A Human Aware Mobile Robot Motion Planner. In IE EE Tranactions on Robotics, 23: 874-883. Seoul, SouthKorea: IEE Robotics and Automation Society. 